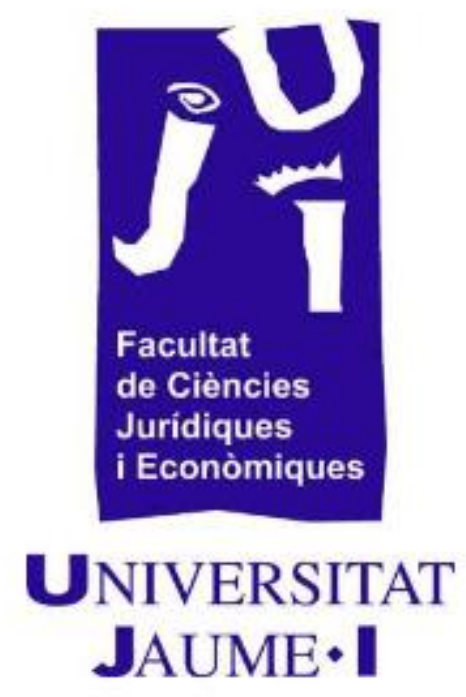

\title{
EMOTIONAL INTELLIGENCE AND LEADERSHIP
}

Author: Desislava Antonova Ivanova

Tutor: Jacob Guinot Reinders

DEGREE OF BUSINESS ADMINISTRATION

AE1049 - FINAL PROJECT DEGREE

COURSE: 2015-2016 


\section{TABLE OF CONTENTS}

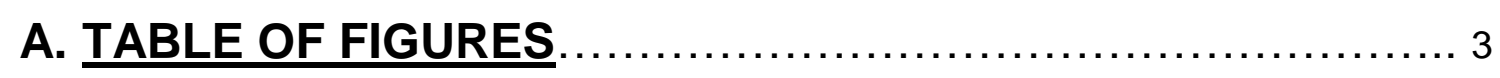

ABSTRACT

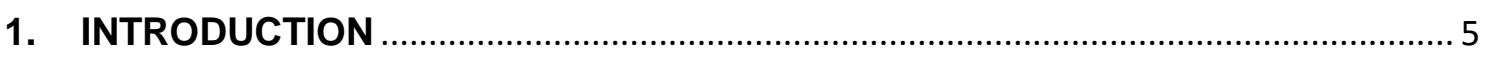

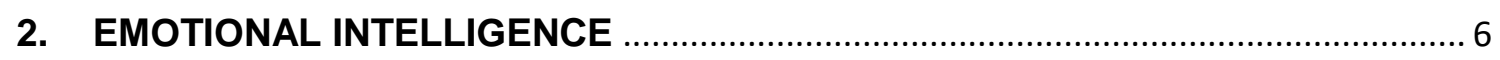

2.1 THEORETICAL FRAMEWORK

2.2 EMOTIONAL INTELLIGENCE AT WORK

3. MODELS OF EMOTIONAL INTELLIGENCE ....................................................... 9

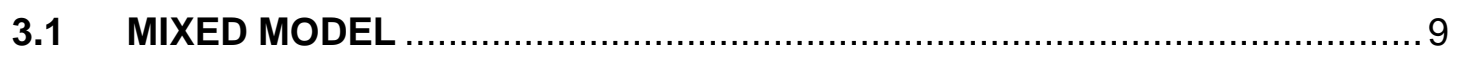

$3.2 \quad$ ABILITY MODEL

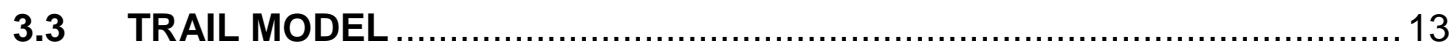

4. IMPORTANCE OF EMOTIONAL INTELLIGENCE ……………………………...... 14

5. LEADERSHIP AND EMOTIONAL INTELLIGENCE …………………………...... 17

5.1 TRANSFORMATIONAL LEADERSHIP AND EMOTIONAL INTELLIGENCE ..18

5.2 TRANSACTIONAL LEADERSHIP AND EMOTIONAL INTELLIGENCE .....22

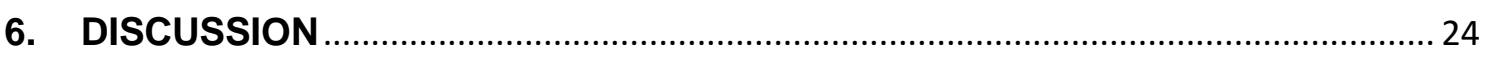

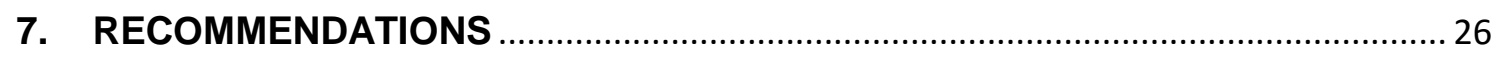

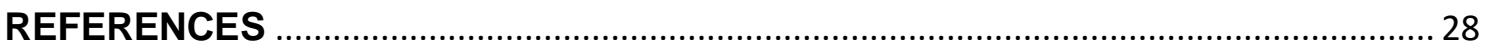

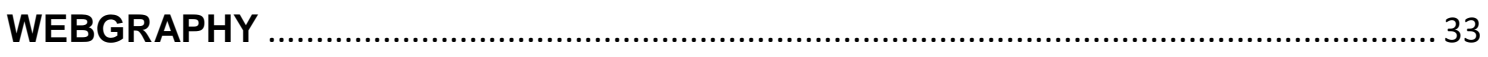




\section{A. TABLE OF FIGURES}

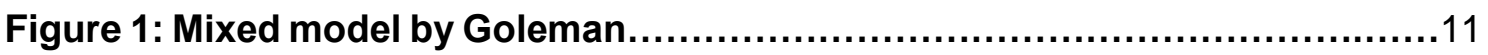

Figure 2: Salovey and Mayer model.............................................................. 12

Figure 3: Additive effect of transformational leadership.............................19

Figure 4: Establishing Linkages between Emotional Intelligence and

Transformational Leadership ..................................................... 22 


\section{ABSTRACT}

Purpose: The main purpose of this document is to evaluate claims that emotional intelligence is significantly related to transformational and transactional leadership behaviour and also to analyse and explore the importance of emotional intelligence and the ability to manage our emotions in order to be more successful in every organization and personal life. In order to do so, the document first seeks to clarify the idea of emotional intelligence and all the components, identifying the importance and benefits of this type of intelligence in organizations.

Design/ methodology / approach: This document represents a theoretical review of emotional intelligence, starting from the need to understand what it is, how to understand it, how to improve it, what are the benefits in organizations and what types of leadership use to be more emotional intelligent. In this document are used references to existing literature related to emotional intelligence and leadership. This references are obtained from the database of the University Jaume I.

Findings: Emotional Intelligence has a positive impact on organizations. Emotional intelligence is the key to our relationships and interactions are successful and are beneficial for all parties involved. Individuals with high emotional intelligence are able to cope with different situations in a much more effective way. They are also able to manage stress and cope with the changes happening within companies. Emotional intelligence also influence on the physical and mental health. The emotional fitness is important especially in leadership role whose essence is getting others to execute their jobs more effectively. In addition, it has been found that the transformational and transactional leader have certain traits that match the dimensions of emotional intelligence.

Originality / value: The document aims to analyze different approaches to emotional intelligence, leadership, paying attention on transactional leadership and transformational leadership, and how to improve emotional intelligence.

Key-words: emotional intelligence, leadership, transactional leadership, transformational leadership, emotions, factors of emotional intelligence, benefits of emotional intelligence.

Paper type: literature review 


\section{INTRODUCTION}

We constantly communicate and connect with different people on a daily basis. As a result, every day we deal with emotions at some level that affect the way we behave towards others and that shape our behaviour and forge the decisions that we make. In order to connect easily and in the right way with people and ourselves, by making the right decisions, we need to be able to understand emotions and how they affect us. This is the key role of Emotional Intelligence (EI) which according to the field of psychology refers to the control that one has over his or her emotions and the ability to understand and interpret them as well as those of others (Mayer and Salovey, 1990).

The Pioneer in the study of El, Goleman (2001) who focuses on emotional intelligence on the workplace describes it as "... being able to motivate oneself and persist in the face of frustrations; to control impulse and delay gratification; to regulate one's moods and keep distress from swamping the ability to think; to empathize and to hope". But being emotionally intelligent doesn't mean to only apply these qualities at work but also in life. The ability to understand what other people are feeling and experiencing emotionally it's usually a non-verbal process that influences our connection with others. In this way the use of Emotional intelligence leads eventually to personal achievements, happiness and professional success. That is way, Goleman (2001) defends El by stating that "... is twice as important as the cognitive ability". Also El is considered, among many authors and psychologists, to be a vital part of a successful leadership, performance and team work in many organizations (Welch 2003; Vakola, 2004; Goleman, 1996). Those who are able to manage properly their emotions and to label and understand the emotions of others, can achieve positive outcomes in the line of production, apply a model of a behavior to be followed, set a positive tone, inspire and motivate an entire organization (Turner, 2004). El is something that can be learned and is not something that is acquired (Goleman, 2000). But whether one will be able to apply the knowledge in life once it learns about $\mathrm{El}$ is a different story. Usually while in the face of stress load we may fail to apply El by neglecting and dismissing our best intentions. In order to be able to shift behaviors that stand up under stress and pressure we have to be able to stay emotionally aware and be able to control stress and or overcome stress. All this can be achieved by being emotionally intelligent.

For this theoretical review, which it is mainly studied El and its benefits on people and in particular on the leaders, it has divided in four main points. First is the theoretical framework of El. Subsequently, it is analyzed the three main models of emotional intelligence. After, emotional intelligence it is related with transformational and 
transactional leadership. Finally, a general conclusion about the importance of emotional intelligence in the workplace, for leaders and people in general, mentioning its benefits. The methodology followed to do this theoretical review it was, firstly search for the principal authors of El. Then, I looked for other articles and researches about the relationship between emotional intelligence and leadership, focusing this theoretical review on transformational and transactional leadership. Finally, I propose some suggestions about the development of this type of intelligence.

\section{EMOTIONAL INTELLIGENCE}

\subsection{THEORETICAL FRAMEWORK}

Goleman (1996), defined emotional intelligence (EI) as: "Understanding one's own feelings, empathy for the feelings of others and the regulation of emotion in a way that enhances living." Emotional intelligence is the ability to perceive, understand and manage both your own emotions and the emotions of others. Emotional intelligence facilitates relationships with others, handling stress state, overcoming obstacles and achieving goals (Salovy and Mayer 1990).

Mayer, Salovey and Caruso (1990), define El as the capacity to understand emotions to enhance thinking. It includes the potential to exactly perceive emotions, to access and generate emotions so as to assist thought, to comprehend emotions and emotional knowledge. It also includes to be able to reflectively regulate emotions so as to promote emotional and intellectual growth.

Salovy and Mayer (1990) were among the earliest to put forward the name "emotional intelligence" to describe the capacity of people to deal with their emotions. They explained emotional intelligence as "the subset of social intelligence that involves the ability to monitor one's own and others' feelings and emotions, to discriminate among them and to use this information to guide one's thinking and actions".

In companies, as in the daily life of people, the ability to use one's emotions in a positive and constructive way in relationship with others is emotional intelligence. Having great intellectual abilities may make you a superb fiscal analyst or legal scholar, but a highly developed emotional intelligence will make you a candidate for CEO or a brilliant trial lawyer" (Goleman, 1997, p. 76). In his book "Working with Emotional Intelligence", the author argue that people with high level of El have not only greater mental health but 
also a great job performance and leadership skills. He also say that El represent about $67 \%$ of the abilities deemed necessary for a greater performance in leaders, and mattered twice as much as technical expertise or Intelligence quotient (IQ) (Goleman, 1998).

All definitions are rooted in emotions. Everything revolves around how they are identified, controlled and can be "used" productively; both in our interior, that is, what we can do with our emotions, our behavior and our relationships with others; and what we can do with the emotions "of others", ie that we can identify or generate in others.

In addition, all of the above definitions, are an expression which includes different but complementary skills and abilities to academic intelligence. The set of competencies of emotional intelligence determine the behavior of people and their reactions and how they face life and how they communicate with others. Therefore, El is the intelligent use of emotions.

In an organization, the most common emotions can be for example satisfaction, enthusiasm, joy, confidence, anger, fear, worry, anxiety, frustration, sadness, among many others. According to the above definitions, the ability to manage emotions does not mean censoring, but involves understand them, accept them and channel them to our benefit and that of the organization. Therefore, it is very important to properly manage emotions, especially leaders, because otherwise, can block up communication, conflicts can occur, interpersonal relationships deteriorate, which affects the performance of the functions and the level of business productivity will be low. Analyzing the above information it can be inferred that leaders with a high level of emotional intelligence, have the ability to control their emotions and think before acting. They can manage their emotions in order to not get nervous easily and feel comfortable in change and ambiguity. This is often a difficult set of skills to master, especially under high levels of stress.

With EI, leadership is more effective, because El helps foster better professional relationships, it increases personal effectiveness and success, and it enhances a leader's critical, analytical, and strategic thinking skills, because it allows to the leader to gain new perspectives on challenging situations (George, 2000).

In resume, Emotional Intelligence is the ability to deal with our emotions and comprehend emotions and feelings of others through empathy in order to facilitate relationships, manage stress, handle frustration and overcome all types of obstacles in the daily life 
and achieve goals and objectives. El allows us to understand our emotions to handle them in the best way.

\subsection{EMOTIONAL INTELLIGENCE AT WORK}

In recent times, the rapid expansion of the global market, the advancement of technologies, the constant changes that companies face as well as the diversity of work today, have increased the demand for emotionally intelligent employees. Because of this, the topic managing emotions in the workplace have become a very popular topic of critical research between organizational behaviorists (Hochschild, 1983; Rafaeli \& Sutton, 1989; Van Maanen \& Kunda, 1989). There are many courses on emotional intelligence created by specialists in professional development and have been very successful but some authors recommend that the formation of emotional intelligence can best be achieved "At work" (Clarke, 2004; Sluiss, Williams, and Hoeksema, 2002). In this way people can develop skills that occur through leadership or participation in teamwork, projects and professional tasks (Baron et al., 1999; Blumenfield, Soloway, Marx, Krajcik, y Palincsar, 1991; Evered y Selman, 2001; Vince, 2004). The El competencies and skills that can be acquired in the workplace are as tangible benefits such as higher performance changes and increases in merit pay and rank (Grewal, Kadis, Gall, Lopes, and Salovey, 2006).

In the workplace, employees high on El would be more aware of their own emotions and from others, which in turn, could lead companies to better profits and less unnecessary expenses and also they perform substantially better than employees low in EI (Rooy and Chockalingam, 2004). Moreover, employees high in this type of intelligent show more confidence in their roles, which permit them to face demanding tasks in positive way (Thomas, Tram, Susanna 2006). According to Lopes (2006), El promote to develop strong and positive relationships with partners and co-workers and perform efficiently in work teams. The author suggest that this benefits performance of workers by providing emotional support and instrumental resources needed to succeed in their roles. Considering that nowadays in companies, there may be many stressful situations, emotional intelligent employees, in this cases, have better resources to cope with stressing situations and demanding tasks. This enable them to outperform in those situations, which is a benefit for the company (Lopes, 2006). According to many authors, the quality of the relationship between employees and the leader or supervisor could interfere with the results of the subjective rating of the evaluation of job performance. 
Employees who are emotionally intelligent, devote more of their time working on managing its relationship with supervisors. Therefore, the probability of obtaining better results in performance assessment is higher for employees with high El for employees with low El (Janssen, Onne and Van 2004).

Marchant (2013) suggest that "a business in which the staff are emotionally intelligent is one which enables them to work together to maximum effectiveness. This can only increase the organization's success, however measured". According to the author, El is applicable to every human interaction in business as staff motivation and also customer service, brainstorming to company presentations, etc.

Given the above information, a business or organization in which the staff are emotionally intelligent is one of this type of organizations which enables them to work together to maximum effectiveness. The benefits of this is the increase of organization's success.

\section{MODELS OF EMOTIONAL INTELLIGENCE}

Currently there are three principal models of El: mixed model, ability model and trait model.

\subsection{MIXED MODEL}

The mixed model was introduced by Goleman and this model is concentrated on El as a wide range of skills and competencies that drive leadership performance.

Goleman (1995) has studied and analyzed the emotional intelligence and affirms that the development of emotional intelligence includes five levels. In addition, the author states that the development of emotional intelligence has to go through the five levels gradually.

According to Daniel Goleman, this five main elements of Emotional intelligence are:

- Self-awareness: Individuals that are emotionally intelligent maintains an awareness of the way they behave and they are aware of the labels that are placed upon them. The self-awareness leads individuals to be able to operate within the norms established for each particular role (Averill, 1980).

Scheff (1983) describe emotions as being culturally specific, where people have to interpret and appraise the cultural expectations of certain emotional displays, and act 
accordingly. Individuals who are self-aware comprehend the role they must represent, a role that is assigned by the community in which they interact. The self-awareness allows individuals to put priority to the different problems so that less important problems are separated and set aside while the most urgent problems are addressed (Abraham, 1999; George, 2000). This can be especially useful when working in teams. People who have a high level of self-awareness are easy to work together and solve problems more easily. The most important problems are easier to perceive and solve. Minor conflicts are easily swept aside by emotionally intelligent individuals in order to take precedence of the project issues.

- Self-regulation. It is the ability to control your own emotions in healthy ways. This capacity helps to the person to be able to take initiative and also to adapt to changing situations. People who lack this ability has to constantly struggle with the unpleasant tensions but, people who have this capacity recover much more quickly from setbacks and disappointments of life (Goleman, 1996, p80).

- Internal Motivation. Emotional tendencies that guide or facilitate reaching goals. It is the ability to perform actions by oneself without the need to be driven by other factors to keep the creative mind and find solutions. According to Goleman (1996), people who have this skill tend to be more productive and effective in all companies. It is the ability to self-induce emotions and positive moods, as confidence, enthusiasm and optimism.

- Empathy. The capacity to understand the emotional reactions of other people. This is only possible when one has achieved self-awareness. This is because people cannot understand others until they understand themselves. It is about 'Awareness of others' feelings, needs, and concerns" (Goleman, 1996).

- Social skills. It is the ability to develop and maintain good relationships, communicate clearly and effectively, be able to inspire and influence others, capacity to work well in a team, and manage conflict. According to Goleman's model this ability is about Adeptness at inducing desirable responses in others". Social skills consists of four different skills: leadership, the ability to establish relationships and maintain friendships, the ability to resolve conflicts and the ability for social analysis. Therefore, this interpersonal intelligence is the ability to understand others (Goleman, 1996, p72). 
Figure 1: Mixed model by Goleman

SELF

SOCIAL

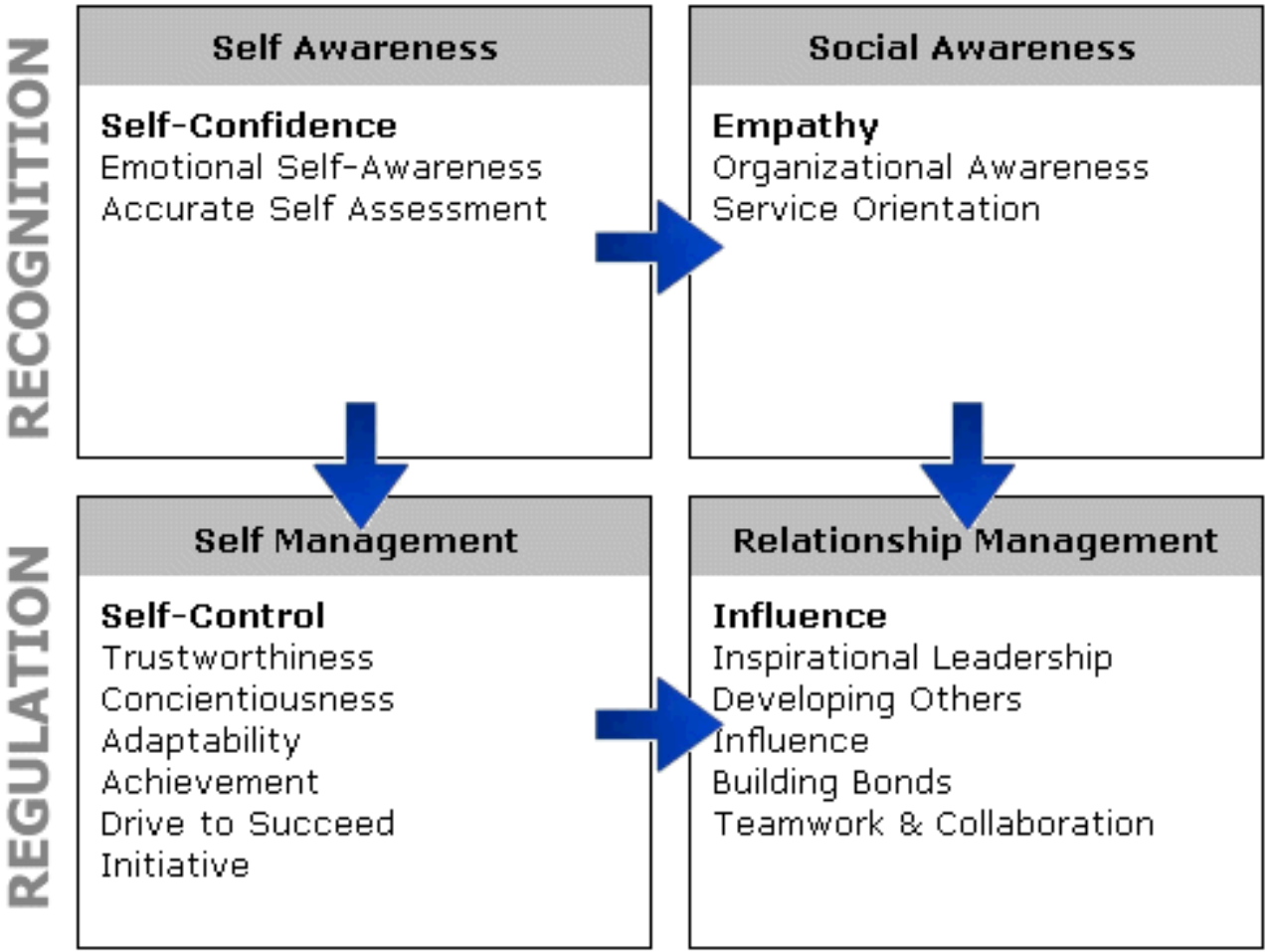

SOURCE: The Emotionally Intelligence Workplace. Cary Cherniss y Daniel Goleman, 2001

\subsection{ABILITY MODEL}

Emotions may interact with thinking and allow people to make better decisions (Lyubomirsky et al. 2005). The ability model was developed and studied by Salovey and Mayer (1997) and their conception of El strives to define El within the confines of the standard criteria for a new intelligence. They defined El as "the capacity to reason about emotions, and of emotions, to enhance thinking. It includes the abilities to accurately perceive emotions, to access and generate emotions so as to assist thought, to understand emotions and emotional knowledge, and to reflectively regulate emotions so as to promote emotional and intellectual growth" (Salovey, et, al.,2004). 


\section{Figure 2: Salovey and Mayer model}

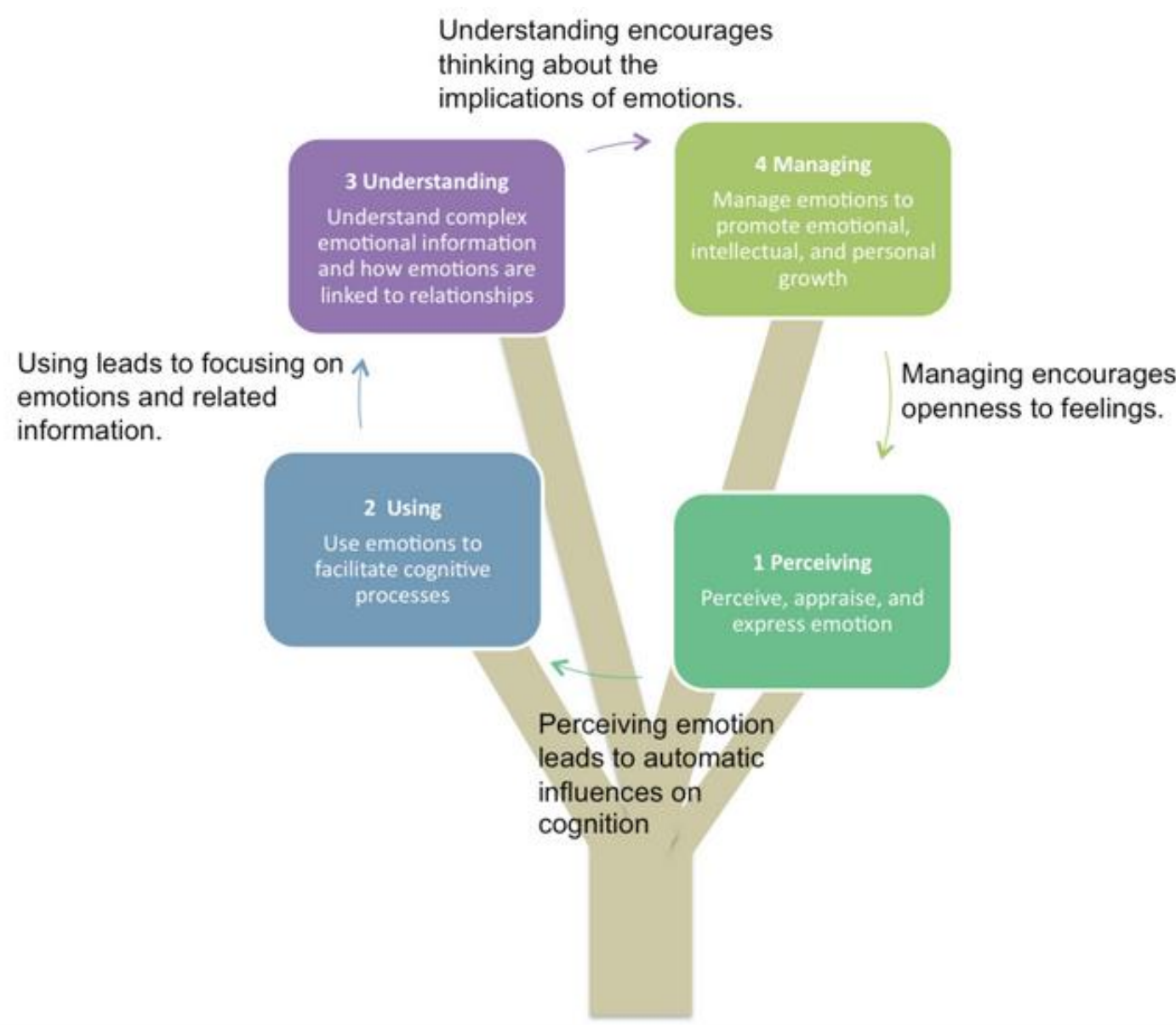

Source: http://psychtastic.com/2015/02/emotional-intelligence-salovey-mayer/

The ability model, take emotions into account as practical sources of information that help one to make sense of and navigate the social environment (Mayer and Salovey, 1997). The model suggest that individuals differ in their ability to process information of an emotional nature and in their ability to relate emotional processing to a wider cognition. This ability is seen to manifest itself in certain adaptive behaviors. The model claims that El includes four types of abilities:

The first one is the ability of Perceive emotions. This is the ability to detect and interpret emotions in faces, pictures, voices, and cultural artefacts-including the ability to identify one's own emotions. The ability to perceive emotions represents a basic aspect of emotional intelligence as it makes all other processing of emotional information possible.

The second one is, the capacity of Using emotions, which is the ability to harness emotions to facilitate various cognitive activities like thinking and problem solving. Person who is emotionally intelligent is able to capitalize fully upon his or her changing moods in order to best fit the task at hand. 
The third one is related to Understanding emotions. It is the ability to comprehend emotional language and differentiate complicated relationships among emotions. For example, understanding emotions encompasses the ability to be sensitive to small variations between emotions, and the ability to acknowledge and describe how emotions evolve over time.

The last one is the ability to manage emotions. Managing emotions means to have the ability to regulate emotions in both ourselves and in others in order to be able to harness them, even negative ones and manage them to achieve intended goals.

In a research made by Bradberry (2003), the ability El model has been criticized for lacking face and predictive validity in the workplace. However, in terms of construct validity, ability EI tests have great advantage over self-report scales of El because they make a comparison between individual maximal performance and standard performance scales and do not rely on individuals' approbation of descriptive statements about themselves (Brackett and Mayer, 2003).

\subsection{TRAIL MODEL}

Petrides (2007) suggest a conceptual distinction between the ability based model and a trait based model of El. In his book called "The location of trait emotional intelligence in personality factor space" the author say that, Trait El is "a constellation of emotional selfperceptions located at the lower levels of personality." Therefore, trait El refers to an individual's self-perceptions of their emotional abilities. This definition of El include behavioral dispositions and self-perceived abilities. It is measured by self-report, as opposed to the ability based model. The ability based model refers to actual abilities, which have proven highly resistant to scientific measurement. Trait El should be investigated within a personality framework (Petrides and Furnham, 2001).

Acording to Petrides and Furnham (2001), in his book "On the dimensional structure of emotional intelligence", thay consider that the trait El model is general and subsumes the Goleman model discussed above. The conceptualization of El as a personality trait leads to a construct that lies outside the taxonomy of human cognitive ability. This is a significant distinction in as much as it bears directly on the operationalization of the construct and the theories and suppositions that are formulated about it. 


\section{IMPORTANCE OF EMOTIONAL INTELLIGENCE}

Emotional Intelligence can be defined as an ability to manage emotions. Therefore, EI can be worked on and improved. El is important not only in the company but in the lives of people, because the relationships between people are better handled. For example, when there is a problem that causes a feeling of anger, if the person has a high level of emotional intelligence, it would be able to identify these emotions, understand, analyze and manage them in a way that does not affect others. "Various facets and components of El have been claimed to contribute to success and productivity in the workplace. El is claimed to predict occupational success because it influences one's ability to succeed in coping with environmental demands and pressures" (Bar-On, 1997). It has been found that workers who have a high level of emotional intelligence are also declared to be adept at designing projects that involve infusing products with feelings and aesthetics (Mayer \& Salovey, 1997). On the other hand, it has been observed that managers with high Emotional Intelligence, show superior performance both in terms of contextual performance (teamwork and cohesiveness) and task performance (quality of job completed) (Carmeli, 2003). In this case, people with high level of El have a high performance at work, being able to work in team and the quality of job, generally speaking is high. According to McClelland (1973) academic knowledge and intelligent quotient (IQ) are not enough for good job performance. Gardner (1983) explain that Comprehension and knowledge is not enough. Success in work and life does not depend only of IQ. Social or interpersonal intelligence is differentiation of success in certain professions. This means that a person with a high level of academic knowledge or a high $I Q$, would not necessarily be able to handle your emotions well so that it can adequately address any situation that may arise within the company. People with high IQ are not always able to handle stressful situations or teamwork if not possess qualities and skills emotional intelligence. To be successful and have a high performance in the company is necessary to have not only intellectual but also emotional intelligence.

Other observations and studies made by Lopes, Salovey and Straus (2003), show that analysts and clerical staff of the finance department with a higher level of Emotional Intelligence on the Mayer, Salovey, and Caruso EI test (MSCEIT) are able to obtain better performance bonus and achieve greater ranks than those scoring lower on the test. Emotional Intelligence increase the possibility of the use of constructive conflict with notable correlations between collaboration and awareness of own emotions, control of own emotions, discussion of own emotions, recognition of own emotions, and 
management of others' emotions (Jordan and Troth 2002). Thus, it is quite compelling the evidence supporting the positive role of El.

The ability to deal with our emotions and emotions of others in the best way, affects different aspects as the performance at work, helping you to lead and motivate others or navigate and manage the social complexities of the workplace. On the other hand, El also influence on the physical and mental health. The first step to improving El is to learn how to relieve stress. This is an important step because if people are not able to manage their emotions, they are not going to be able to manage stress. High level of stress can produce problems with health such as blood pressure, suppress the immune system, increase the risk of heart attack, etc. In addition, a person capable of controlling stress can prevent depression and anxiety. Being able to control emotions can avoid many mental problems. Goleman (2001) found that the emotionally competent individual encounters significantly less perceived stress than the emotionally incompetent. El also affects relationships in the way that when person is able to understand emotions and how to control them, it will be easy to express how you feel and understand how others are feeling. This is important because allows people to communicate more effectively and build stronger relationships, both at work personal life.

Goleman $(1995,1998)$ explains in his book that the emotional brain learns differently the thinking brain. Dozens of experts in nearly 500 companies emphasize the crucial role of El in the best performance of any work "intelligence quotient (IQ) and technical skills are important, but El is the sine qua non of leadership". A supervisor can be very smart and have the necessary skills to perform the jobs such as studies and knowledge but stress that is present in the workplace, can cause emotional reactions. Therefore, a high level of El can help the leader to confront and handle these reactions in the best way.

According to Mayer and Salovey, (1990) the most effective leaders have in common one crucial way that they all have a high degree of emotional intelligence. Intelligence quotient and technical skills are also important, but they are the entry-level requirements for executive positions. Without El, a person can have the best training in the world, an incisive, analytical mind, and an endless supply of smart ideas, but he still won't make a great leader. Another interesting data is that $90 \%$ of the difference between real leaders and managers is average El. This has been proven in competency models of 188 organizations (Goleman, 1998). In addition, resent studies show that, managers who can't handle their emotions like anger, reduce employee's willingness to go above and beyond in their work and increase employee turnover (Koning and Kleef, 2015). According to a recent research made by the authors, leader's expression of happiness 
can bring out positive emotions in followers that enhance their work performance and increase their liking for the leader. Conversely, a leader's expression of anger could either enhance performance in the case that followers think that the leader is not pleased about their work, or reduce performance if it brings out negative emotions.

According to Welch (2003), El is an essential factor. He said that El enables teams to increase their performance. Moreover, in his research he found that the most effective teams are the $\mathrm{El}$ ones and that everyone and every team can improve and obtain a higher levels of El.

In addition, Turner (2004), say that $\mathrm{El}$ is the softer component of the total intelligence and it is present both in professional life and personal life of people. The traditional IQ is related to the ability to learn, reason and understand. The author argues that IQ contributes only $20 \%$ to the success of people while the ability to understand and interact with people contributes $80 \%$. In this case, the EQ is critical to the effectiveness of leadership.

El has a positive impact on organizational incomes. For example, a study made by Goleman (1998) in 200 companies obtained results that indicate that $1 / 3$ of productivity is explained by technical skills, and 2/3 El skills. In the case of executive positions, $4 / 5$ of the results are explained by this kind of skills. Goleman (1998) states that a company income grew by $2 \%$ for each $1 \%$ improvement in the emotional environment. Another study found that $34 \%$ higher profit growth in organizations with high-El managers (University of Maryland).

On the other hand, the main cause of failure of executives is the difficulty in managing change, do not work well together and poor interpersonal relationships (Center for Creative Leadership). Competencies and skills of El strengthen the capacity of the company for its own development, its members and the community. According to the information provided above, Emotional Intelligence, among other benefits, it helps people to work better together and improves interpersonal relationships.

Emotional intelligence has been linked to the leadership at work (Caruso, Mayer and Salovey, 2005); the capacity for empathy is related to the level of moral development (Gozálvez, 2000), and this has also been linked with the leadership (Daft, 2006). 
El have numerous benefits. Emotional intelligence is positively correlated with better social relations during work performance and in negotiations. El is also positively correlated with higher life satisfaction, self-esteem and lower levels of insecurity or depression and it is negatively correlated with poor health choices and behavior. Having high levels of El can give to all people a real advantage in today's competitive working environment. It is all about the ability to recognize and understand the personal emotions and personal skill at managing and dealing with other people's emotional states. Put simply, it is the ability to problem solve with or without emotion.

\section{LEADERSHIP AND EMOTIONAL INTELLIGENCE}

There are numerous definitions of leadership, however these definitions have always been debatable. Most scholars agree that the concept of leadership does not ascribe to one specific definition. However, one of the definitions of leadership is provided by Burns (1978) in his landmark publication, leadership: "Leaders inducing followers to act for certain goals that represent the values and the motivations - the wants and needs, the aspirations and expectations - of both leaders and followers". A leader is a person who is able to influence others. It is a reference person within a group. $\mathrm{He} / \mathrm{she}$ is able to transmit, motivate and lead the team forward (Antonakis, Cianciolo and Sternberg, 2004). Lord and Maher (1991) argue that leadership is fundamentally a process result of a social perception, being the essence of it being perceived as a leader for others. The leader also is a person who inspires confidence and contribution each person getting their best. Normally, the leader pursues both the good of the company, as the particular good of each of its members and gets everyone to feels identified with the project and ensures that everyone feels part of the objectives of the company. Moreover there is some consensus assume that leadership is needed to guide organizations and human resources to strategic objectives (Zaccaro, 2001). Thus, people who are leaders, get a motivated team to achieve the goals.

There are certain traits and characteristics that differentiate people who are considered leaders of those who do not (Bass, 1990). This approach is based on different theories of personality aimed at identifying individual differences between people. Some of the personal attributes that characterize the leaders are: high levels of energy, intelligence, intuition, foresight and persuasion. According Yukl (1992) this approach allows to say what kind of person is right for leadership positions but does not indicate whether the leader will be successful or not. However, there are some characteristics that seem to 
be related to propose of effective leadership. These characteristics are a high energy levels, stress tolerance, integrity, emotional maturity or emotional intelligence and selfconfidence (Bass, 1990; Kirkpatrick \& Locke, 1991; Yukl, 1992). The first two characteristics (high energy levels and stress tolerance) possible to meet the urgent demands with which they often face those in positions of leadership. The first two characteristics (high energy levels and stress tolerance) possible to meet the urgent demands with which they often face those in positions of leadership. On the other hand, Integrity and emotional maturity enabled the leader to maintain cooperative relations with subordinates, superiors and all people in general. Finally self-confidence makes the leader can achieve objectives more effectively and difficult to carry out a successful influence over his followers.

In a research made by Bardzill and Slaski (2003), they found that organizational leaders must recognize the importance of Emotional Intelligence behavior and reward it actively. A positive strengthening of an Emotional Intelligence environment make certain the development of a service in the organization. This is orientated to the climate. Emotional elements are in the dynamics of many aspects of modern organizations. In this case, the role of El is important and should be considered when designing organizational policies, processes and procedures.

\subsection{TRANSFORMATIONAL LEADERSHIP AND EMOTIONAL INTELLIGENCE}

Transformational leadership is a style of leadership where a leader works with subordinates to identify needed change. This type of leader is able to creating a vision to guide the change through inspiration, and implement the change in tandem with involved members of a team.

Bass (1985) describes the type of transformational leadership from the effects that the leader have over his followers. Transformational leaders cause changes in their followers from them aware about the importance and value that are of the results obtained after performing the assigned tasks. In addition, the leader encourages followers to transcend their personal interests under the objectives of the organization. This builds trust, respect and loyalty from followers and also motivation to achieve more than what was originally expected. 


\section{Additive Effect of Transformational Leadership}

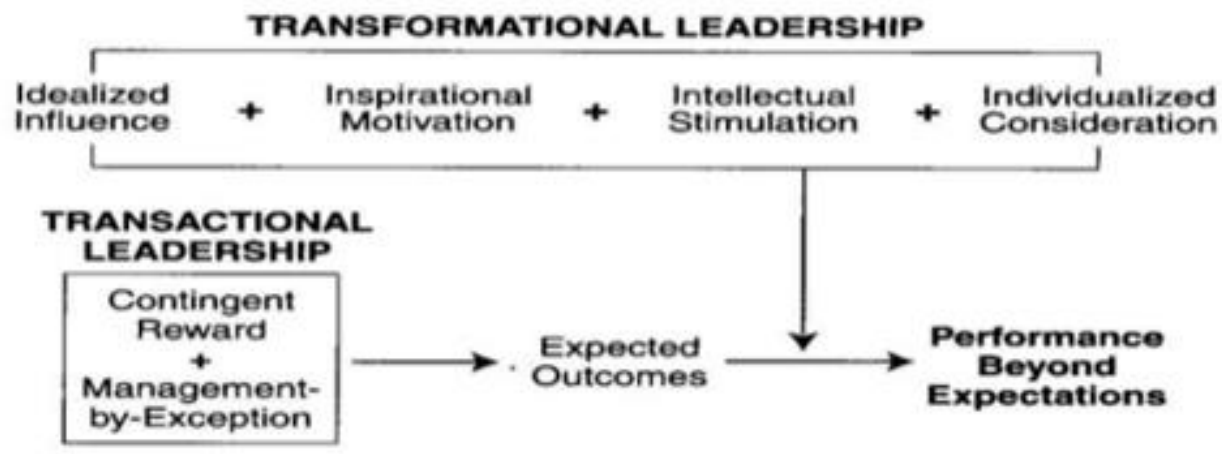

Source: Adapted from "The implications of Transactional and Transformational Leadership for Individual, Team, and Organizational Development", by B. M. Bass and B. J. Avolio, 1990a. Research in Organizational Change and Development, 4, 231-272

Transformational leadership try to improve the motivation, morality, and job-performance of followers through different mechanisms. These mechanism include connecting the follower's sense of identity to a project and to the collective identity of the organization. This type of leader also mean to be a role model for followers in order to inspire them and to raise their interest in the project. Other mechanism used by transformational leadership is to challenge followers to take greater ownership for their work, and understanding the strengths and weaknesses of followers, allowing the leader to line up followers with tasks that improve their performance (Bass and Avolio, 1990).

Burns (1978) built his theory about transformational leadership. Mainly it has been developed by Bass (1990). This model is the most researched and the most studied by Avolio (1999) and Antonakis (2004). This theory understands leadership as an influence process in which leaders influence their followers.

The concept of transformational leadership is the most complete component of the theory of leadership. This theory tend to view leadership as a shared by several leaders from different levels of the same organization, however the charismatic leadership approach 
tends to focus on the individual personality of certain leaders process. A transformational leader constantly seeks to change personal values among the followers in the way that they can go beyond their self-interest for the good of the company. (Bass, 1985). According to Bass (1985) there are 4 components to transformational leadership, sometimes referred to as the 4 I's. This components are idealized influence (II), Inspirational Motivation (IM), Individualized Consideration (IC) and Intellectual Stimulation (IS). This type of leaders are described as people who hold positive expectations for followers making them believe they can do things in the best way. The extent to which a leader is transformational, is measured first, in terms of his influence on the followers. As its name implies, transformational leadership is a process that changes and transforms people. Various studies have found a relationship between transformational leadership and the efficacy of organizations (Avolio, 1999; Avolio, Bass, \& Jung, 1995; Dumdum, Lowe, \& Avolio, 2002).

Some of the features of transformational leadership described by Bass (1985) are for example the charisma. Charisma is the possession of highly-developed emotional and social communication skills. People who have charisma, are a brilliant and effective communicators who communicate emotions very well, especially positive emotions (Riggio, 2011). Analyzing the components of personal charisma, according to Riggio (2011) there are three types of emotional skills and three social components. The first emotional skill is the ability to Emotional Expressiveness. This means to be able to accurately and spontaneously convey emotional messages through nonverbal channels. Actually, it is expressiveness that is the most visible aspect of charisma. The second skill is the ability of emotional sensitivity. This is the ability to read and precisely "decipher" others' emotions and read nonverbal cues. This is where the charismatic person arise "in tune" and "empathetic" with others. The last emotional ability is the emotional control which is the capacity to regulate and control your emotional communication and expressions and also be able to hide felt emotions, or mask them with a different emotional. According to the author, Charismatic people are good emotional actors. The three social components are principally, Social Expressiveness, social sensitivity which means to be able to read the characteristics or "demands" of the social situation in order to behave appropriately, and social control. This last one means to have self-confidence in social situations.

Taking into account this characteristic of transformational leadership, there is a relationship between emotional intelligence and charismatic person because there is an emotional and social skills in common with emotionally intelligent people. 
Leaders behave in such a way that they are taken as models by his followers, they want to imitate them. They are admired, respected and trusted them. They demonstrate high levels of ethical and moral behavior. Other characteristic is the inspiration, leaders motivate and inspire their followers, encouraging the spirit group and generate future expectations. Intellectual stimulation is another characteristic of transformational leadership. Leaders encourage their followers to be innovative and creative from generating new questions and formulating old problems in new terms ideas. Individual errors or ideas that differ from those of the leader cannot criticize.

Other attribute to transformational leadership is the individualized consideration. Leaders pay special attention to the individual needs of personal development of each of the followers; the particular differences are recognized; monitoring is personalized but is not seen as a control, leaders play a guiding role.

Bass (1998) considers transformational leaders allow their followers successfully face conflict or stress, providing safety and tolerance when there is uncertainty. Taking into account information on emotional intelligence, we can deduce that this is related to transformational leadership. Therefore, to enable the person to help his followers to cope with stress or have tolerance for uncertainty, the leader must be emotionally intelligent and have the ability to do the same and influence others.

Studies have analyzed the IE (Barling, Slater and Kelloway, 2000) find that there is a relationship between EI and effective leadership. Bass and Avolio (1990) argue that transformational leadership, provides organizational change, which is, according to these researchers, the emotional intelligence of leader is closely linked to the use of transformational behavior. Butler and Chinowsky (2006) found that El is related to transformational leadership, like the capacity for empathy. Some researchers (eg, Cann, 2004) emphasize that $\mathrm{EI}$ is an element of great importance for transformational leadership, since the focus of leadership is the management of complex dynamic person to them and social, including the role of emotions in the organization. Other research (eg Sosik and Megerian, 1999) conclude that emotional intelligence is a strong requirement for effective leadership.

Analyzing the relationship between transformational leadership and emotional intelligence, it is established that elements of this type of intelligent such as empathy, self-awareness and motivation have direct positive relation with transformational 
leadership feature such as individual influence, individualized consideration and inspirational motivation. It is inferred that leader who is emotionally intelligent will be able to influence his followers with his individual personality and motivate them very well. Also with enhanced El competency the empathy will be more pronounced, and he can give individualized consideration to his followers. The model is represented in the following diagram (Kumar, 2014).

TABLE 4: Establishing Linkages between Emotional Intelligence and Transformational Leadership

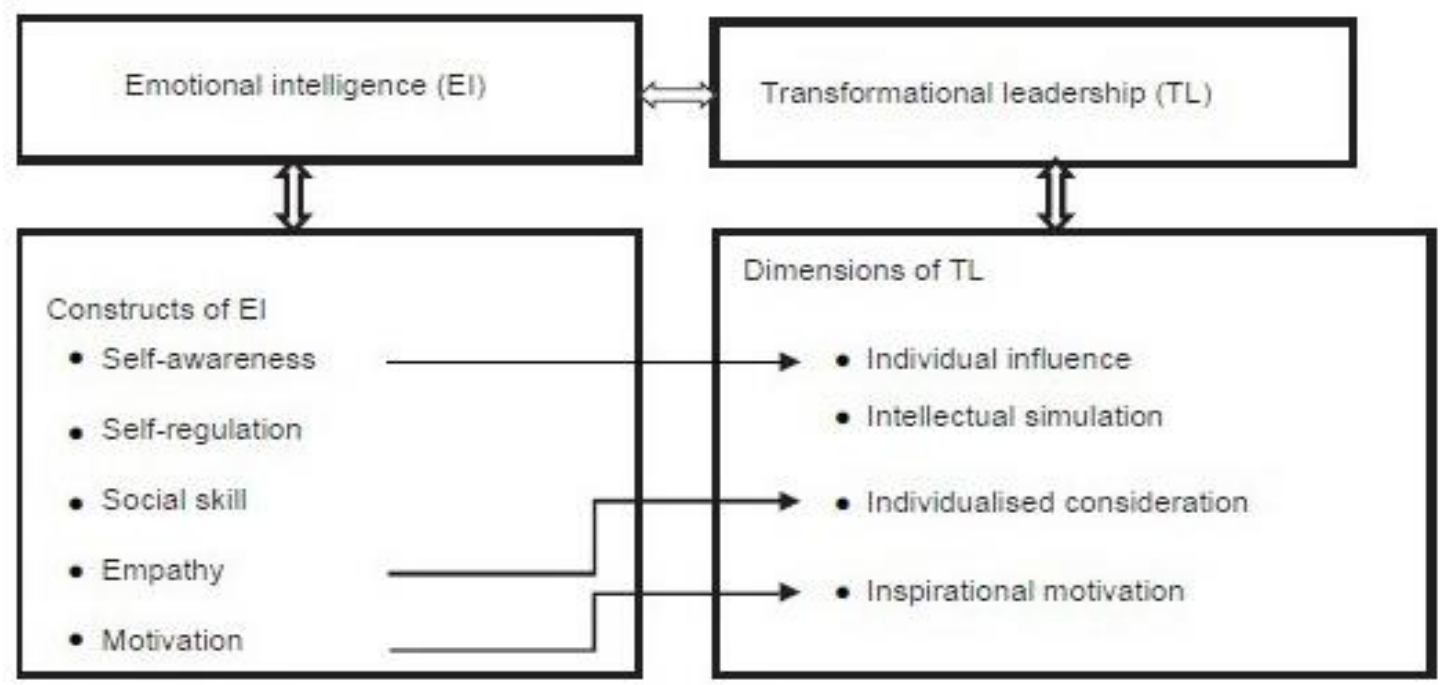

Source: Kumar, Sanjay. "Establishing Linkages between Emotional Intelligence and Transformational Leadership". Ind Psychiatry J 23.1 (2014)

\subsection{TRANSACTIONAL LEADERSHIP AND EMOTIONAL INTELLIGENCE}

Burns (1978) also makes a distinction between transformational leadership and transactional leadership. Burns (1978) described transactional leaders as leaders that give a special importance to the work standards, assignments, and task-oriented goals. In comparison to transformational leadership, transactional leadership occurring when the leader recompense or disciplines the follower with regards to performance (Bass and Avolio, 1994). Taking into account the hierarchy of needs of Maslow, transactional leadership works at the basic levels of need satisfaction, where transactional leaders focus on the lower levels of the hierarchy.

Transactional leadership makes followers being motivated by personal interests rather than being influenced by their leaders to transcend their own needs towards the benefit of the organization, typical of transformational leadership (Hargis, Wyatt and Piotrowski 2011). Transactional leadership usually occurs when leaders reward or, negatively 
intervenes (sanction) taking into account performance of the followers. According to Bass and Avolio (1994), usually transactional leadership consist of two sub dimensions:

Contingent reward: refers to an interaction between leader and follower guided by reciprocal exchanges. The leader identifies the needs of followers and makes a compromise between the needs of the group and of each person. The reward or the sanctions are given in terms of meeting the objectives. Management by exception: the leader intervenes only when necessary to make corrections or changes in the behavior of followers. In general interventions are negative and critical so that the objectives are not diverted from its course.

Transformational leaders look towards changing the future to inspire followers and accomplish goals, whereas transactional leaders seek to maintain the status quo, not aiming for progress (Judge and Piccolo 2004).

The relationship between transactional leadership and El is that according to Weisinger (2000), there is a high interrelation between Transactional leadership and SelfMotivation. This relationship can be explained in the way that the author associates selfmotivation with productivity. Weisinger (2000) affirm that when a person is selfmotivated, then he/she will be able to begin a task or assignment, and move ahead to the full completion, all the while dealing with any setbacks that may appear. Therefore, Self-Motivation with Self- Awareness and less degree Emotional Mentoring, concentrate attention on the process of task completion, rather than the other, which makes their stronger association with transactional rather than transformational leadership appear logical in hindsight (Weisinger, 2000). 


\section{DISCUSSION}

By means of researches as well as scholarly reviews, this theoretical review has provided information about the importance of emotional intelligent in organizations and the positive impact that it have on leaders. In addition, it has be found that some leaders have characteristics of El.

El is a set of abilities and skills that allow people to process information about emotions efficiently and precisely. According to the models of $\mathrm{El}$, the emotionally intelligent individual has abilities related to perceiving, using, understanding, and managing emotional information.

Transformational leadership is the most contemporary and effective way of management and is shown to be greatly dependent to the levels of El (Atwater and Yammarino, 1993). George (2000), propose that leaders high in El are able to recognize, appraise, predict and manage emotions. In this way leaders are able to empower work and motivate team members. The author also argue that "El of the team leader is important to the effective functioning of the team. The emotionally intelligent team leader also provides a transformational influence over the group."

Transformational Leadership behaviors have been related to leadership effectiveness and business unit outcomes (Lowe et al., 1996; Waldman et al., 1987). More specifically, Bass (1997), suggest that, transformational leaders produce better financial performance than transactional leaders. In addition, Keller (1995) found that there are certain aspects of transformational leadership that make group performance greater. Furthermore, Lowe et al. (1996) found that in most of the studies, transformational leadership behaviors as charisma, individualized consideration and intellectual stimulation are closely related to leadership effectiveness. Another interesting fact is that the success of leaders depends on two factors. On the one hand, the success of leaders depends on the interaction that has the leader with group members or leadership style. On the other hand, it depends on the degree of control that the leader have over certain situations. Additionally, there are three variables that help achieve control in different situations: the leader's relationship with the group, the structure of tasks and power of the leader (Contingency Theory of Fiedler and Chemers, 1984). This aspects of transformational leadership that make the group performance greater as the good interaction with the group members or the degree of control of leaders in some situations is also related to El. Social skills of El is one of this characteristics that help people to have a good relationship with others. El is "essential to effective team interaction and productivity" (Prati, et. al., 1998). Also skills 
as self-awareness and self-regulation which means to have control of the emotions, are helpful to face different type of situations in the best way.

Taking in to account all the information, this characteristics as charisma, individual stimulations and other as empathy that is a characteristic of transformational leadership, also coincides with El. The information analyzed in this review also found that people with high $\mathrm{El}$ is more effective, and this may be the reason of the transformational leadership effectiveness because this type of leader possess El skills. In addition, emotionally intelligent leaders are capable of improving their empathetic capabilities and also influence, motivate, inspire, encourage and persuade their followers which ultimately can help them climb the leadership ladder themselves (George, 2000).

Transactional leaders are those who are task-motivated. So, they use to begin a task and move ahead to the full completion. To do so, this type of leaders need the selfmotivation. In this case they also have El skills as self-motivation and self-awareness which explain the relationship between transactional leadership and EI. The fact that such leaders have less emotional intelligence traits than transformational leaders, could explain why some authors argue that in many situations, transformational leaders are more effective and have better performance than transactional leaders.

Fiedler and Chemers (1984) suggest that transactional leadership perform best in situations of high control or low control, in contrast, relationship-motivated leader (transformational) leaders perform best in situations of moderate control. But, according to the literature reviewed, there is not found sufficient evidence, what type of leadership is better than another because it depends on the situation. Effective leadership required to match the situation to particular leadership style. But what is clear is that leaders with high level of $\mathrm{El}$ are more effective. So, it is true that $\mathrm{El}$ is beneficial and helps leaders to face different situations both stress and uncertainty. It is shown that leaders who have a high level of El have better relationships and better team work among other benefits. 


\section{RECOMMENDATIONS}

El can develop two types of factors: personal factors and social factors. Personal factors are related to the dimensions of emotional self-awareness, self-regulation and motivation. On the other hand, social factors develop empathy, the ability to understand others and social skills that focus on the influence, good communication, leadership, teamwork skills among others. Emotions should be considered as a source of information (Goleman, 2000).

It's good to control what you think in order to understand the emotions, because emotion and thought provoke a feeling.

According to the theoretical review, El can be developed by using the elements of the mixed model proposed by Goleman (1995).

El can be developed by Self-awareness, one of the elements of the elements of the mixed model. Self-awareness means to be able to control your own emotions in healthy ways. Being able to connect with the personal emotions, is a key element to understanding how they influences thoughts and actions. Mindfulness practice, builds self-awareness and also reduces stress. This type of practice consist to focusing the attention on the present moment without judging the situation. Being able to appreciate the moment, may help to shift the preoccupation, and brings a larger perspective on life. Developing emotional awareness can help to manage stress. Emotional awareness can be developed by learning the mindfulness meditation.

Emotional Intelligence can be developed using self-management. When people are overwhelmed by stress, they sometimes can lose control of their emotions. Being able to manage emotions could be helpful to make a certain and constructive decisions. Staying emotionally present and being able to manage stress, people can learn to receive all type of information without letting override the thoughts and self-control. In this way people will be able to make better choices that allow the control of impulsive feelings and behaviors, manage emotions in healthy ways, take initiative and adapt to changing circumstances than can be present not only at work but also in daily life.

El also can be developed by using social awareness. Social awareness is the ability that allow people to understand the nonverbal cues others constantly send. In order to be able to understand emotions of others, you will have to know how to suspend your thoughts. This ability will allow people to experience nonverbal cues that change from one moment to the next. It is important to try to pay attention what you feel and what you 
experience emotionally as you listen to others. Everything that you experience is bringing information about yourself.

Using relationship management also can be helpful to developed El. Working well with others is important especially in organizations. This is a process that begins with emotional awareness and the ability to recognize, admit and understand what other people are feeling or experiencing.

Some authors recommend that the formation of El can best be achieved "At work" (Clarke, 2004; Van der Sluiss, Williams, and Hoeksema, 2002). In the workplace, people could be able to develop skills that occur through leadership or participation in projects, professional task or working in teams (Baron et al., 1999; Blumenfield, Soloway, Marx, Krajcik, y Palincsar, 1991; Evered y Selman, 2001; Vince, 2004).

Today we can say that from the initial charges to the highest charges there is a need to have El bases in order to thrive within a company.

"Educating the mind without educating the heart is no education at all."

Aristotle 


\section{REFERENCES}

Avolio, B.J. \& Bass, B.M. (1995). Individual consideration viewed at multiple levels of analysis: A multiframework for examining the diffusion of transformational leadership. Leadership Quarterly, 46, 188-218.

Atwater, L.E., and Yammarino, F.J. (1993), Personal Attributes as Predictors of Superiors' and Subordinates' Perceptions of Military Leadership. Human Relations, 46, 645-668

Atwater, L., \& Yammarino, F. J. (1992). Does self-other agreement on leadership perceptions moderate the validity of leadership and performance predictions? Personnel Psychology, 45, 141-164.

Ashkanasy, N. M., and Daus, C. S. (2005), Rumors of the Death of Emotional Intelligence in Organizational Behavior are Vastly Exaggerated. Journal of Organizational Behavior, 26, 441 452

Bass, Bernard (2008). Bass \& Stogdill's Handbook of Leadership: Theory, Research \& Managerial Applications (4th ed.). New York, NY: The Free Press. pp. 50,623.

Bass, B. M., Avolio, B. J., Jung, D. I. \& Beson, Y. (2003). Predicting unit performance by assessing transformational and transactional leadership. Journal of Applied Psychology, 207-218.

Bass, B. M. \& Steidlmeier, P. (1999). Ethics, character and authentic transformational leadership behavior. Leadership Quarterly, 181-217.

Bass, B.M. (1997), Does the Transactional-Transformational Leadership Paradigm Transcend Organizational and National Boundaries? American Psychologist, 139 -139

Bass, B. M., \& Avolio, B. J. (1997). Full range leadership development: Manual for the multifactor leadership questionnaire. Palo Alto, CA: Mindgarden

Bass, B.M., and Avolio, B.J. (1994), Improving Organizational Effectiveness through Transformational Leadership. Thousand Oaks. CA: Sage.

Bass, B. M., \& Avolio, B. J. (1990). Developing transformational leadership: 1992 and beyond. Journal of European Industrial Training, 21-27

Bass, B. M. (1985). Leadership and performance beyond expectations. New York: Free Press. 
Bar-On, R. (2006). The Bar-On model of emotional-social intelligence (ESI). Psicothema 18, 13-25.

Bar-On, R. (1997). Emotional Quotient Inventory: Technical manual. Toronto: Multi-Health Systems.

Barrett, G.V. (2001). Emotional intelligence: the Madison Avenue approach to science and professional practice. Symposium presented at the annual meeting of the Society for Industrial Organizational Psychology, April, 2001, San Diego, California

Barling, J., Moutinho, S. and Kelloway, E.K. (2000), Transformational Leadership and Group Performance: The Mediating Role of Affective Commitment. Manuscript revised for publication, School of Business, Queen's University, Kingston, Ontario.

Barling, J., Weber, T. and Kelloway, E.K. (1996), "Effects of transformational leadership training on attitudinal and fiscal outcomes: a field experiment", Journal of Applied Psychology, Vol. 81, pp. 827-32.

Butler, C. and Chinowsky, P. (2006). "Emotional Intelligence and Leadership Behavior in Construction Executives." J. Manage. Eng., 22(3) 119-125.

Beasley, K. (1987, May). The emotional quotient. Mensa, the British Mensa Magazine.

Bradberry, T., \& Greaves, J. (2009). Emotional intelligence 2.0. San Francisco, CA: Publishers Group West.

Bradberry, T., \& Su, L.D. (2006). Ability-versus skill-based assessment of emotional intelligence. Psicothema, pp. 59-66

Burns, J. M. (1998). Leadership. New York: Harper and Row.

R. Riggio y S. Murphy (2013). Multiple intelligencies and leadership. Mahwah, NJ: Erlbaum.

Copper R.K. (1997). Applying emotional intelligence in the workplace. Training \& Development Vol. 51, pp.31-38

Furnham, A. \& Stringfield, P. (1998). Congruence in job-performance ratings: a study of 360-degree feedback examining self, manager, peer and consultant ratings. Human Relations, 51, 517-530 
Goleman, D. (1996). Inteligencia emocional. Barcelona: Kairós

Goleman, D. (1998). Working with emotional intelligence. New York: Bantam Books

Goleman, D. (2006). Social intelligence: The new science of social relationships. New York, NY: Bantam Books.

George, J.M. (2000). Emotions and leadership: The role of emotional intelligence. Human Relations, 1027-1055

Hargis, Michael B.; John D. Wyatt; Chris Piotrowski (2011). "Developing Leaders: Examining the Role of Transactional and Transformational Leadership Across Contexts Business.". Organization Development Journal: 51-66

Harms, P. D., \& Credé, M. (2010b). Remaining issues in emotional intelligence research: Construct overlap, method artifacts, and lack of incremental validity. Industrial and Organizational Psychology, 154-158.

Hunter, J. E., \& Schmidt, F. L. (1996). Intelligence and job performance: Economic and social implications. Psychology, Public Policy and Law, 447-472.

Howell, J.M. and Avolio, B.J. (1993), Transformational Leadership, Transactional Leadership, Locus of Control, and Support for Innovation: key Predictors of Consolidated Business-un it Performance.' American Psychological Association, 891 -902

Hochschild, A. R. (1979). Emotion work, feeling rules, and social structure. American Journal of Sociology, $85(3), 551-575$

Janssen, Onne; Yperen, Nico W. Van (2004). "Employees' Goal Orientations, the Quality of LeaderMember Exchange, and the Outcomes of Job Performance and Job Satisfaction". Academy of Management Journal: 368-384

Judge, Timothy A., and Ronald F. Piccolo (2004) "Transformational and Transactional Leadership: A Meta-Analytic Test of Their Relative Validity." Journal of Applied Psychology 89.5: 755-68.

Kumar, S. (2014) "Establishing Linkages between Emotional Intelligence and Transformational Leadership". Ind Psychiatry J 23.1

Kark, R., Shamir, B., \& Chen, G. (2003). The two faces of transformational leadership: Empowerment and dependency. Journal of Applied Psychology, 88 (2), 246-255. 
Lewis, K. M. (2000). When leaders display emotion: How followers respond to negative emotional expression of male and female leaders. Journal of Organizational Behavior, 221-234

Lopes, Paulo N.; Grewal, Daisy; Kadis, Jessica; Gall, Michelle; Salovey, Peter (2006-01-01). "Evidence that emotional intelligence is related to job performance and affect and attitudes at work". Psicothema. Pp. 132-138.

Miller, M. (2009). Transformational leadership behaviours and empathy with action. Transformation: An International Journal of Holistic Mission Studies, 45-59

Mayer, J., Roberts, R., \& Barsade, S.G. (2008). Human abilities: Emotional intelligence. Annual Review of Psychology, 507-536.

Mayer, J.D., \& Salovey, P. (1997). What is emotional intelligence? Emotional development and emotional intelligence: Implications for educators. New York: Basic Books.

Mayer, J. D., and Geher, G. (1996), Emotional Intelligence and the Identification of Emotion. Intelligence, $22,89-113$

Masi RJ, Cooke RA. (2000), Effects of transformational leadership on subordinate motivation, empowering norms and organizational productivity. Int J Organ Anal. 8:16-47

Petrides, K.V., \& Furnham, A. (2000). On the dimensional structure of emotional intelligence. Personality and Individual Differences, European Journal of Personality 29 (2) 313-320.

Petrides, K.V., \& Furnham, A. (2001). Trait emotional intelligence: Psychometric investigation with reference to established trait taxonomies. European Journal of Personality, 425-448.

Petrides, K.V., \& Furnham, A. (2003). Trait emotional intelligence: Behavioural validation in two studies of emotion recognition and reactivity to mood induction. European Journal of Personality, 39-75.

Palmer B, Walls M, Burgess Z, Stough C. (2001). Emotional intelligence and effective leadership. Leadersh. Organ Dev J. 22:5-10

Ross, S.M., and Offermann, L. R. (1997), Transformational Leaders: Measurement of Personality Attributes and Work Group Performance. Personality and Social Psychology Bulletin, 1078-1086

Rafaeli, A., \& Sutton, R. I. (1987). The expression of emotion as part of the work role. Academy of Management Review, 23-37 
Salovey, P. \& Mayer, J. D. (1990). Emotional intelligence. Imagination, Cognition and Personality, 9(3), $185-211$

Salovey, P., \& Grewal, D. (2005). The science of emotional intelligence. Current Directions in Psychological Science, 14, 281-285.

Salovey, P.; Mayer, J.; Caruso, D. (2004), "Emotional Intelligence: Theory, Findings, and Implications", Psychological Inquiry, pp. 197-215

Sy, T.; Tram, S.; O'Hara, L. A. (2006). "Relation of employee and manager emotional intelligence to job satisfaction and performance". Journal of Vocational Behavior: 461-473.

Sosik, J. J., \& Megerian, L. E. (1999). Understanding leader emotional intelligence and performance: The role of self-other agreement on transformational leadership perceptions. Group and Organization Management, 340-366

Turner, N. and Barling, J. (2000), Moral Reasoning and Transformational Leadership: an Exploratory Study. Manuscript Submitted for Publication, School of Business, Queen's University, Kingston, Ontario, Canada

Van R., David L; Viswesvaran, C. (2004). "Emotional intelligence: A meta-analytic investigation of predictive validity and nomological net". Journal of Vocational Behavior 65, 71-95

Weisinger, H. (2000), Emotional Intelligence at Work: The Untapped Edge for Success. San Francisco: Jossey-Bass

Wong, C.-S. and Law, K. S. (2002), The Effects of Leader and Follower Emotional Intelligence on Performance and Attitude: An Exploratory Study. The Leadership Quarterly, 13, 243-274

Welch J. (2003), The best teams are emotionally literate. Ind Commer Train.; 35:168-71

Vakola M, Tsaousis I, Nikolaou I. (2004), The role of emotional intelligence and personality variables on attitudes toward organizational change. J Manage Psychol.; 19:88-110 


\section{WEBGRAPHY}

https://www.psychologytoday.com/blog/cutting-edge-leadership/201103/measuringpersonal-charisma-emotional-intelligence-and-savoir

https://www.psychologytoday.com/blog/cutting-edge-leadership/201103/measuringpersonal-charisma-emotional-intelligence-and-savoir

https://www.mindtools.com/pages/article/transformational-leadership.htm

http://changingminds.org/disciplines/leadership/styles/transactional_leadership.htm

https://www.entrepreneur.com/article/245755 